CLINICAL STUDY

\title{
Raloxifene and body composition and muscle strength in postmenopausal women: a randomized, double-blind, placebo-controlled trial
}

\author{
Didy E Jacobsen, Monique M Samson, Marielle H Emmelot-Vonk and Harald J J Verhaar \\ Department of Geriatric Medicine, University Medical Centre Utrecht, Room B05.256, PO Box 85500, 3508 GA Utrecht, The Netherlands \\ (Correspondence should be addressed to H J Verhaar; Email: h.j.j.verhaar@umcutrecht.nl)
}

\begin{abstract}
Objective: To compare the effects of raloxifene and placebo on body composition and muscle strength. Design: Randomized, double-blind, placebo-controlled trial involving 198 healthy women aged 70 years or older conducted between July 2003 and January 2008 at the University Medical Centre, Utrecht, The Netherlands.

Methods: Participants were randomly assigned to receive raloxifene $60 \mathrm{mg}$ or placebo daily for 12 months. Measurements were taken at baseline, 3, 6, and 12 months, and change from baseline was calculated. Main outcome measures were body composition (bioelectrical impedance analysis), muscle strength, and muscle power (maximum voluntary isometric knee extension strength, explosive leg extensor power, and handgrip strength).

Results: At 12 months, the body composition of women taking raloxifene was significantly different from that of women taking placebo: fat-free mass (FFM) had increased by a mean of $0.83(2.4) \mathrm{kg}$ in the raloxifene group versus $0.03(1.5) \mathrm{kg}$ in the placebo group $(P=0.05)$, and total body water had increased by a mean of 0.6 (1.8) litres in the raloxifene group versus a decrease of 0.06 (1.1) litres in the placebo group $(P=0.02)$. Muscle strength and power were not significantly different.

Conclusion: Raloxifene significantly changed body composition (increased FFM; increased water content) compared with placebo in postmenopausal women.
\end{abstract}

European Journal of Endocrinology 162 371-376

\section{Introduction}

Gonadal hormone production decreases during the menopause, leading to changes in body composition, such as a decrease in fat-free mass (FFM) and muscle strength $(1,2)$. The menopause-related decrease in FFM is ascribed to several factors, namely, estrogen and/or progesterone deficiency, changes in muscle and/or adipose tissue metabolism, modification of eating behaviour, modification of lifestyle, environmental factors, genetic predisposition, and reduction in energy expenditure (3). The decrease in FFM and muscle strength often results in diminished mobility and functionality and in more falls.

Hormone therapy prevents the postmenopausal loss of bone and change in body composition (4). Studies have shown that hormone replacement therapy (HRT) prevents the shift in body fat distribution to a more central location (5-7) and diminishes the loss of muscle strength (8-15). Unfortunately, HRT use is accompanied by adverse side effects, such as an increased risk of breast cancer and cardiovascular disease (16), and for this reason its long-term use is not advocated.
A different type of therapy is with selective estrogen receptor modulators, such as raloxifene. Raloxifene acts as an estrogen agonist on the arterial vasculature, bone, and lipid metabolism and as an estrogen antagonist on the breast and uterus $(17,18)$. To our knowledge, few studies have investigated the effect of raloxifene on body composition $(19,20)$, and none has investigated the effect of raloxifene on muscle strength. We conducted a randomized, double-blind, placebo-controlled trial to assess the effects of raloxifene on body composition and muscle strength and power in elderly women.

\section{Methods}

This randomized, double-blind, placebo-controlled study was part of a larger study, the details of which have been published previously (21). The institutional review board of the University Medical Centre Utrecht approved the study protocol and all participants provided written informed consent. The study was conducted from July 2003 to January 2008. 


\section{Participants}

Most women were recruited by means of direct mailing to women aged 70-80 years old whose addresses were selected by the municipal register of five cities in the province of Utrecht. Women were sent a letter explaining the study and a short questionnaire to collect demographic details. Of the women who returned the questionnaire, those who were considered potentially eligible for inclusion were invited to come for a screening visit. If they fitted the inclusion and exclusion criteria, they were randomized after giving informed consent.

Inclusion criteria were good health, age 70 years or older, and body mass index (BMI) between 18 and $35 \mathrm{~kg} / \mathrm{m}^{2}$. Exclusion criteria were steroid therapy or other drugs affecting muscle mass taken during the last 6 months; history or presence of any malignancy; undiagnosed abnormal vaginal bleeding in the past year; presence or history of endometrial hyperplasia with or without atypia; presence or history of cardiovascular, cerebrovascular, or thromboembolic disorders; current liver or renal disease or history of this condition; uncontrolled hypertension (systolic blood pressure $\geq 170 \mathrm{mmHg}$ systolic and/or diastolic blood pressure $\geq 105 \mathrm{mmHg}$ ); osteoporosis: Z-score $<-2$; bone disease other than osteoporosis such as Paget's disease, osteomalacia, or bone metastases; alcohol abuse (average intake of more than four alcohol-containing units per day); smoking more than ten cigarettes/day; use of sex hormones, corticosteroids, insulin, anticoagulants, or enzyme-inducing drugs; treatment with raloxifene within the last 6 months; known hypersensitivity to raloxifene; presence of any condition, concomitant disease, intercurrent illness, or resultant therapy that would interfere either with the participants' compliance or with the results of the study and/or their evaluation; major problems with locomotion; cognitive impairment (mini mental state examination, MMSE <24); and participation in another study.

\section{Measurements}

The following parameters were studied:

Body composition Body composition was measured by a bioelectrical impedance analyzer (BIA), a commonly used valid and sensitive method (22-24). Bioelectrical impedance measurement is an indirect method and based on the two compartment model. In the twocompartment model, the body is divided into two distinct compartments: body fat and FFM. The principle of BIA is that FFM, which mainly consists of electrolytecontaining water, readily conducts an applied current, whereas fat does not or only does minimally. BIA determines the electrical impedance, which can then be used to calculate an estimate of total body water (TBW). TBW can be used to estimate fat-free body mass and difference with body weight and body fat. The reproducibility in measuring TBW and FFM will approximate the 0.99 test-retest correlation (25-27). The sensitivity of BIA has been proven to be accurate in long-term studies $(25,28)$. These studies had significant correlations to dual X-ray absorptiometry and total body isotope counting (K40).

Bioelectrical impedance measurements were taken on the right side of the body using a tetrapolar BIA 101 impedance analyzer (RJL Systems, Detroit, MI, USA). A current of $800 \mu \mathrm{A}$ at a signal frequency of $50 \mathrm{~Hz}$ was generated by a BIA, and was applied to the subject through electrodes that were placed on the wrist and the ankle on one side of the body. All measurements were taken with the participant supine, the arms relaxed at the sides but not touching the body, and thighs separated (29).

Muscle strength and muscle power Maximum voluntary isometric knee extension strength (both legs) was measured as the force applied at the ankle, with the subject seated in an adjustable straight back chair, the lower leg unsupported, and the knee flexed to $90^{\circ}$. Force was measured with a strain gauge and recorded with a strain meter five to maximally seven times, and the highest score was used $(30,31)$.

Explosive leg extensor power (both legs) was assessed with the Nottingham Power Rig. The subject, in a seated position with folded arms, gave a maximal push to a large foot pedal that set a flywheel in motion. The initial flywheel speed reflects the leg extensor power of the subject (32). The measurement was repeated maximally ten times, and the highest score was used.

Handgrip strength (both hands), which is associated with general muscle strength, was measured with a handgrip mechanical dynamometer (33). The best of minimally three and maximally seven attempts for each hand was recorded.

Compliance Drug compliance was checked by counting the number of tablets in the returned blister packs and cartons. Subjects could continue the trial if fewer than 6 days of trial medication was missed in 4 weeks.

\section{Statistical analysis}

Effects were determined as the change from baseline for the two intervention groups at 3,6 , or 12 months. Descriptive statistics were calculated for all variables. Repeated measurement analyses for 3, 6, and 12 months were performed on an intention-to-treat basis.

\section{Results}

In total, 198 women started treatment after randomization (raloxifene $n=101$, placebo $n=97$; Fig. 1 ). There were no significant differences between the groups at baseline (Table 1). Habitual physical activity was measured at baseline, 3, 6, and 12 months, and 


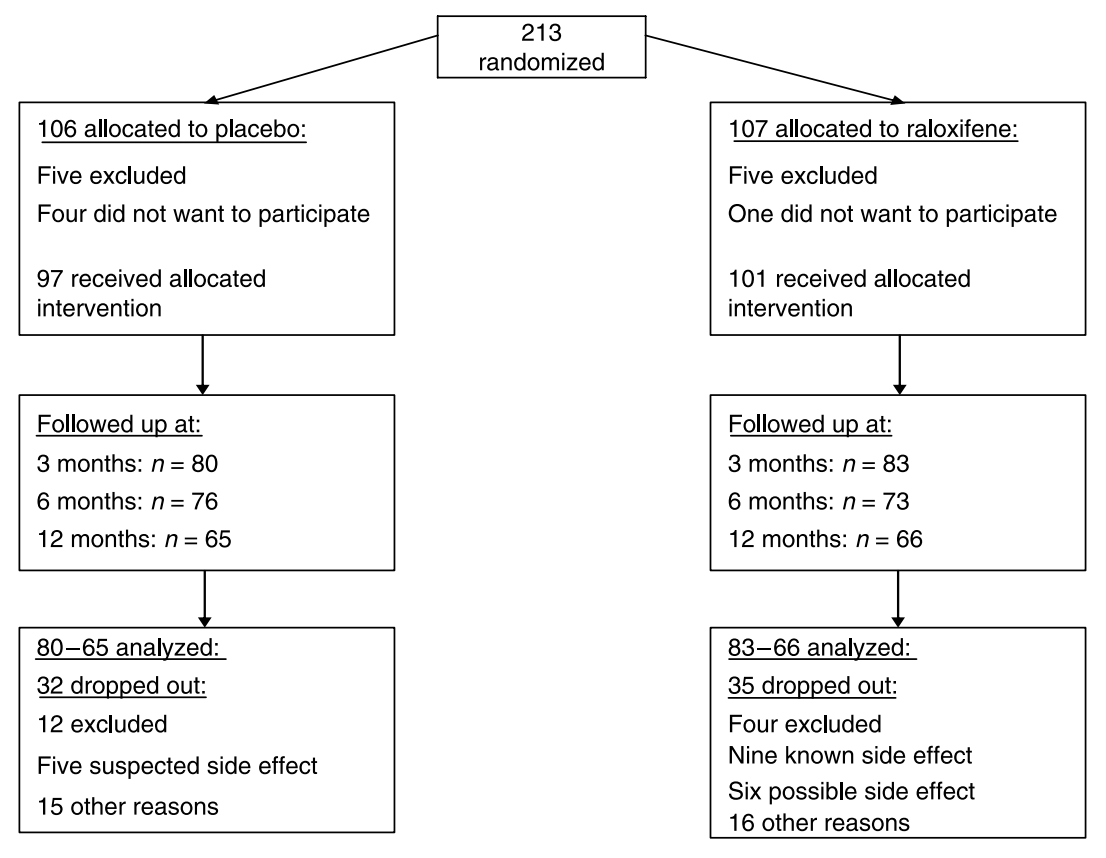

Figure 1 Flow chart of raloxifene and placebo group. physical activity was the same in both groups. Compliance was comparable in both groups, being $96.7 \%$ in the placebo group and $96.5 \%$ in the raloxifene group at 12 months. Total dropout was $33.0 \%$ in the placebo group and $34.7 \%$ in the raloxifene group. Most dropouts occurred between baseline and the 3-month follow-up (raloxifene $17.8 \%$, placebo $17.5 \%$ ). Reasons for dropout are represented in the flowchart (Fig. 1).

Serious adverse events were reported seven times in the placebo group and three times in the raloxifene group. Leg cramps (1-10\%) and flushing (>10\%), recognized side effects of raloxifene, were mainly reported in the raloxifene group.

\section{Body composition}

Repeated measurement analysis showed there to be a significant increase in FFM at 3, 6, and 12 months in the raloxifene group $(P=0.05)$ as well as an increase in

Table 1 Participant characteristics at baseline according to randomization group.

\begin{tabular}{lcc}
\hline & Placebo & Raloxifene \\
\cline { 2 - 2 } Characteristics & $\begin{array}{c}\text { Mean (s.D.) } \\
(n=97)\end{array}$ & $\begin{array}{c}\text { Mean (s.D.) } \\
(n=101)\end{array}$ \\
\hline Age (years) & $73.4(3.2)$ & $73.6(3.2)$ \\
Falls (number) & $0.75(0.43)$ & $0.72(0.45)$ \\
Body weight $(\mathrm{kg})$ & $69.3(9.8)$ & $67.4(13.2)$ \\
BMl $\left(\mathrm{kg} / \mathrm{m}^{2}\right)$ & $26.3(3.6)$ & $25.7(3.9)$ \\
Fat mass $(\mathrm{kg})$ & $26.1(6.6)$ & $25.5(8.0)$ \\
Fat-free mass $(\mathrm{kg})$ & $43.2(3.9)$ & $43.1(4.2)$ \\
Total body water $(\mathrm{kg})$ & $31.6(2.9)$ & $32.3(7.5)$ \\
Smoking & No $(\%)$ & No $(\%)$ \\
& $6.0(24.2)$ & $6.0(23.8)$ \\
\hline
\end{tabular}

TBW ( $P=0.02$; Table 2). At 12 months, the mean increase in FFM was $0.83(2.4) \mathrm{kg}$ in the raloxifene group compared with $0.03(1.5) \mathrm{kg}$ in the placebo group $(P=0.05)$, and the mean increase in TBW was 0.6 (1.8) litres compared with a decrease of 0.06 (1.1) litres in the placebo group $(P=0.02)$.

There were no significant differences in weight, BMI, and fat-mass (FM).

\section{Muscle strength and muscle power}

There were no significant differences in muscle strength and muscle power (maximum voluntary isometric knee extension strength, explosive leg extensor power, and handgrip strength) between the two groups (Table 3).

\section{Discussion}

In this randomized placebo-controlled trial, we investigated the effect of 1 year of raloxifene treatment on body composition and muscle strength in a group of elderly women. Raloxifene affected body composition, significantly increasing the FFM and the TBW content compared with placebo. In contrast, raloxifene did not significantly affect FM, weight, BMI, or muscle strength and power.

Menopause is associated with significant hormonal and metabolic changes. There is an important decrease of the concentration in estrogens and there are changes of body composition. Both body weight and body fat distribution increase with a shift toward an android distribution, and there is a decrease in FFM. 
Table 2 Body composition at 3, 6, and 12 months (repeated measurement analysis).

\begin{tabular}{|c|c|c|c|c|c|c|}
\hline \multirow[b]{3}{*}{ Parameters } & \multirow[b]{3}{*}{$\begin{array}{c}\text { Time } \\
\text { (months) }\end{array}$} & \multicolumn{5}{|c|}{ Change versus baseline } \\
\hline & & Raloxifene & $n=70$ & Placebo & $n=73$ & \\
\hline & & Mean & S.D. & Mean & S.D. & $P$ value \\
\hline \multicolumn{7}{|c|}{ Raloxifene versus placebo } \\
\hline \multirow{3}{*}{ Weight $(\mathrm{kg})$} & 3 & 0.06 & 1.4 & 0.22 & 1.1 & \\
\hline & 6 & 0.04 & 1.8 & 0.1 & 1.8 & \\
\hline & 12 & 0.24 & 2.9 & -0.09 & 2.3 & 0.88 \\
\hline \multirow[t]{4}{*}{ BMI $\left(\mathrm{kg} / \mathrm{m}^{2}\right)$} & 3 & 0.007 & 0.6 & 0.077 & 0.4 & \\
\hline & 6 & 0.006 & 0.7 & 0.06 & 0.7 & \\
\hline & 12 & 0.04 & 1 & -0.03 & 1 & 0.88 \\
\hline & & & $n=68$ & & $n=71$ & \\
\hline \multirow[t]{3}{*}{ Fat mass (kg) } & 3 & -0.14 & 2.2 & 0.2 & 1.6 & \\
\hline & 6 & -0.48 & 3.1 & -0.06 & 2 & \\
\hline & 12 & -0.61 & 3.7 & -0.15 & 2 & 0.13 \\
\hline \multirow[t]{3}{*}{ Fat-free mass (kg) } & 3 & 0.05 & 1.2 & 0.03 & 1.7 & \\
\hline & 6 & 0.47 & 1.8 & 0.09 & 1.8 & \\
\hline & 12 & 0.83 & 2.4 & 0.03 & 1.5 & 0.05 \\
\hline \multirow[t]{3}{*}{ TBWT (litres) } & 3 & 0.04 & 0.9 & -0.01 & 1.3 & \\
\hline & 6 & 0.36 & 1.4 & -0.1 & 1.3 & \\
\hline & 12 & 0.6 & 1.8 & -0.06 & 1.1 & 0.02 \\
\hline
\end{tabular}

BMI, body mass index; TBWT, total body water.

It is unclear whether the commonly observed postmenopausal changes of body composition are related entirely to ageing or are accelerated by estrogen deficiency (34).

This is important because body FM and its distribution correlate with risks of coronary artery disease (5) and certain cancers (35), while lean body mass is associated with muscle strength, which correlates with the prevention of falls, frailty, and disability (36).

In our study, we found an increase in the FFM after supplementation with raloxifene, which could be partly explained by the increase in the TBW content, a known effect of raloxifene supplementation. However, the increase in the TBW content could not explain the

Table 3 Muscle strength and power at 3, 6, and 12 months (repeated measurement analysis).

\begin{tabular}{|c|c|c|c|c|c|c|}
\hline \multirow[b]{3}{*}{ Parameter } & \multirow[b]{3}{*}{$\begin{array}{c}\text { Time } \\
\text { (months) }\end{array}$} & \multicolumn{5}{|c|}{ Change versus baseline } \\
\hline & & Raloxifene & $n=66$ & Placebo & $n=72$ & \multirow[b]{2}{*}{$P$ value } \\
\hline & & Mean & S.D. & Mean & S.D. & \\
\hline \multicolumn{7}{|c|}{ Raloxifene versus placebo } \\
\hline \multirow[t]{4}{*}{ IKES right $(\mathrm{N})$} & 3 & -3.9 & 33.1 & 0.75 & 37.4 & \\
\hline & 6 & 6.1 & 40.6 & 0.64 & 44.3 & \\
\hline & 12 & -1.8 & 47.8 & 2.8 & 44.7 & 0.83 \\
\hline & & & $n=67$ & & $n=69$ & \\
\hline \multirow[t]{3}{*}{ IKES left (N) } & 3 & -5 & 41.9 & 2.2 & 42 & \\
\hline & 6 & -3.3 & 38.1 & 2.4 & 54.5 & \\
\hline & 12 & -5.8 & $\begin{array}{l}48.8 \\
n=70\end{array}$ & 7.5 & $\begin{array}{c}46.7 \\
n=72\end{array}$ & 0.16 \\
\hline \multirow[t]{4}{*}{ HGS right $(\mathrm{kg})$} & 3 & 0.4 & 3.1 & -0.2 & 4.7 & \\
\hline & 6 & -0.13 & 3.5 & -1.4 & 4.4 & \\
\hline & 12 & -0.41 & 4.5 & -0.86 & 4.8 & 0.22 \\
\hline & & & $n=70$ & & $n=75$ & \\
\hline \multirow[t]{4}{*}{ HGS left (kg) } & 3 & 0.97 & 3.5 & 0.41 & 3.9 & \\
\hline & 6 & 0.63 & 3.8 & 1.2 & 9.1 & \\
\hline & 12 & 1 & 4.7 & 1.3 & 9.5 & 0.89 \\
\hline & & & $n=69$ & & $n=66$ & \\
\hline \multirow[t]{3}{*}{ Power rig right $(\mathrm{W})$} & 3 & 2.2 & 26.9 & 4.7 & 25 & \\
\hline & 6 & 9.4 & 28 & 8.2 & 33.7 & \\
\hline & 12 & 9.4 & 24.2 & 3.7 & 26.3 & 0.7 \\
\hline \multirow[t]{3}{*}{ Power rig left $(W)$} & 3 & -0.7 & 26 & 6.5 & 28.5 & \\
\hline & 6 & 8.7 & 26.8 & 11.4 & 33.4 & \\
\hline & 12 & 8.1 & 27.3 & 6.6 & 26.9 & 0.5 \\
\hline
\end{tabular}

IKES, isometric knee extension strength; HGS, handgrip strength. 
whole increase in the FFM, and also the amount of physical activity was comparable between both groups during the study. This means that there is also a real change in body composition with an increase in lean body mass. The results of our study are comparable with some other studies, but in most of these studies there were problems with the design of the study (no blinding, no placebo group, too small groups, and a too short intervention period).

In a previously performed prospective, randomized, controlled, and open-label clinical study, raloxifene was found to significantly promote the shift from android to gynoid fat distribution and to prevent the uptrend of abdominal adiposity and body weight compared with untreated women (37). Another study in postmenopausal women compared the effects of raloxifene (60 mg/day), tibolone ( $2.5 \mathrm{mg} /$ day), and 'no therapy' on body composition over a 12-month period. While there was no significant change in FM or FFM in the raloxifene group, there was an increase in total FM and FM at the trunk in the no therapy group. The authors concluded that raloxifene seemed to prevent postmenopausal changes in body composition. However, this prospective, randomized controlled study did not have a double-blind, placebo-controlled design, in contrast to our study. Also, the groups were very small, with 21 women in the untreated group and 24 women in the raloxifene group (19).

The increase in FFM was not accompanied by an increase in muscle strength and muscle power in our study. Muscle strength is a key factor in maintaining independence in elderly people. There are no other studies concerning raloxifene and muscle strength or power. Studies concerning HRT (estrogen and progestagens) show conflicting results: two randomized controlled trials with no effect $(38,39)$ and three randomized controlled trials with significant increase in muscle strength (11-13).

Our randomized, double-blind, placebo-controlled study had the advantages of a sufficient number of participants and a 12-month study period with four assessment times. The dropout rate of around 30\% was similar to that reported previously in a study in osteopenic women of comparable age (40), which suggests that this may be a consequence of the older age of the participants.

In summary, in this randomized, double-blind, placebo-controlled trial, 1 year of raloxifene treatment led to a significant change in body composition, with an increase in FFM and TBW, in late postmenopausal women. Long-term use of raloxifene may prevent the reduction in FFM, usually seen in postmenopause. Muscle strength and power were not affected. The clinical impact of this finding warrants further research.

\section{Declaration of interest}

The authors declare that there is no conflict of interest that could be perceived as prejudicing the impartiality of the research reported.

\section{Funding}

Financial support for this study was provided by the Dutch Organization for Health Research and Development (Zon M W, number: 2200.0080). The study drugs and the matching placebo were supplied by Eli Lilly BV, The Netherlands.

\section{Author contribution statement}

H J J Verhaar designed the study, developed the research question, wrote the study protocol, obtained ethical approval, obtained grant funding, and implemented this study. H J J Verhaar, M M Samson, and D E Jacobsen participated in its design and coordination. D E Jacobsen drafted the manuscript, with assistance from $\mathrm{H} \mathrm{J} J$ Verhaar, M M Samson, and M H Emmelot-Vonk. All authors have read and approved the final manuscript.

\section{Acknowledgements}

The authors wish to thank Els Mommersteeg, research assistant for taking the measurements and Dr Ingrid B A E Meeuwsen for her contributions to the protocol.

\section{References}

1 Samson MM, Meeuwsen IBAE, Crowe A, Dessens JAG, Duursma SA \& Verhaar HJJ. Differences in variables of muscle strength and functional mobility in healthy subjects in relation to age, height and body weight. Age and Ageing 200029 235-242.

2 Kallman DA, Plato CC \& Tobin JD. The role of muscle loss in the age-related decline of grip strength: cross-sectional and longitudinal perspectives. Journal of Gerontology 199045 M82-M88.

3 Panotopoulos G, Raison J, Ruiz JC, Guy-Grand B \& Basdevant A. Weight gain at the time of menopause. Human Reproduction 1997 12 126-133.

4 Di Carlo C, Tommaselli GA, Sammantino A, Bifulco G, Nasti A \& Nappi C. Serum leptin levels and body composition in postmenopausal women: effects of hormone therapy. Menopause 2004 $11466-473$.

5 Lapidus L, Bengtsson C, Larsson B, Pennert K, Rybo E \& Sjostrom L. Distribution of adipose tissue and risk of cardiovascular disease and death: a 12 year follow-up of participants in the population study of women in Gothenburg, Sweden. BMJ 1984289 $1257-1261$.

6 Hoover LW \& Boote EJ. Londitudinal assessment of intraabdominal fat in postmenopausal women. Annals of the New York Academy of Sciences $2000904520-525$.

7 Hagberg JM, Zmuda JM, McCole SD, Rodgers KS, Wilund KR \& Moore GE. Determinants of body composition in postmenopausal women. Journals of Gerontology Series A: Biological Sciences and Medical Sciences 200055 M607-M612.

8 Phillips SK, Rook KM, Siddle NC, Bruce SA \& Woledge RC. Muscle weakness in women occurs at an earlier age than in men, but strength is preserved by hormone replacement therapy. Clinical Science 199384 95-98.

9 Cauley JA, Robbins J, Chen Z, Cummings SR, Jackson RD, La Croix AZ, LeBoff M, Lewis CE, McGowan J, Neuner J, Pettinger M, Stefanick ML, Wactawski-Wende J \& Watts NB. Effects of estrogen plus progestin on risk of fracture and bone mineral density: the women health initiative randomized trial. Journal of the American Medical Association 2003290 1729-1738.

10 Taaffe DR, Sipilä S, Cheng S, Puolakka J, Toivanen J \& Suominen H. The effect of hormone replacement therapy and/or exercise on skeletal muscle attenuation in postmenopausal women: a year long intervention. Clinical Physiology and Functional Imaging 200525 297-304. 
11 Heikkinen J, Kyllonen E, Kurtilla-Matero E, Willen-Rosenqvist G, Lankinen KS, Rita H \& Vaananen HK. HRT and exercise: effects on bone density, muscle strength and lipid metabolism. A placebo controlled 2 year prospective trial on two estrogen-progestin regimens in healthy postmenopausal women. Maturitas 199726 139-149.

12 Sipila S, Taaffe DR, Cheng S, Puolakka J, Toivanen J \& Suominen H. Effects of hormone replacement therapy and high impact physical exercise on skeletal muscle in post-menopausal women: a randomized placebo-controlled study. Clinical Science 2001101 147-157.

13 Skelton DA, Phillips SK, Bruce SA, Nayor CH \& Woledge RC. Hormone replacement therapy increases isometric muscle strength of adductor pollicis in post-menopausal women. Clinical Science 199996 357-364.

14 Brooke-Wavell K, Prelevic GM, Bakridan C \& Ginsburg J. Effects of physical activity and menopausal hormone replacement therapy on postural stability in postmenopausal women - a cross-sectional study. Maturitas 200137 167-172.

15 Greeves JP, Cable NT, Reilly T \& Kingsland C. Changes in muscle strength in women following the menopause: a longitudinal assessment of the efficacy of hormone replacement therapy. Clinical Science 199997 79-84.

16 Writing Group for the Women's Health Initiative Investigators (2002). Risk and benefits of estrogen plus progestin in healthy postmenopausal women: principal results from the women's health initiative randomized controlled trial. Journal of the American Medical Association $2002288321-333$.

17 Khovidhunkit W \& Shoback DM. Clinical review. Clinical effects of raloxifene hydrochloride in women. Annals of Internal Medicine $1999130431-439$.

18 Ott SM, Oleksik A, Lu Y, Harper K \& Lips P. Bone histomorphometric and biochemical marker results of a 2-year placebocontrolled trial of raloxifene in postmenopausal women. Journal of Bone and Mineral Research 200217 341-348.

19 Tommaselli GA, Di Carlo C, Di Spiezo Sardo A, Bifulco G, Cirillo D, Guida M, Capasso R \& Nappi C. Serum leptin levels and body composition in postmenopausal women treated with tibolone and raloxifene. Menopause 200613 660-668.

20 Lee CC, Kasa-Vubu JZ \& Supiano MA. Differential effects of raloxifene and estrogen on insulin sensitivity in postmenopausal women. Journal of American Geriatric Society 200351 683-688.

21 Jacobsen DE, Samson MM, Schouw YT, Grobbee DE \& Verhaar HJJ. Efficacy of tibolone and raloxifene for the maintenance of skeletal muscle strength, bone mineral density, balance, body composition, cognitive function, mood/depression, anxiety and quality of life/well-being in late postmenopausal women $\geq 70$ years: study design of a randomized, double-blind, double-dummy, placebocontrolled, single-center trial. Trials 2008932.

22 Brummer RJM, Rosén T \& Bengtsson B-Å. Evaluation of different methods for determing body composition, with special reference to growth hormone-related disorder. Acta Endocrinologica $1993 \mathbf{1 2 8}$ 30-36.

23 Xie X, Kolthoff N, Barenholt O \& Nielsen SP. Validation of a legto-leg bio-impedance analysis system in assessing body composition in postmenopausal women. International Journal of Obesity and Related Metabolic Disorders 199923 1079-1084.

24 Pasquali R, Vicennati V, Bertazzo D, Casimirri F, Pascal G, Tortelli O \& Labate AM. Determinants of sex hormone-binding globulin blood concentrations in premenopausal and postmenopausal women with different oestrogen status. Virgilio-MenopauseHealth Group. Metabolism 199746 5-9.
25 Lukaski HC, Bolonchuk WW, Hall CB \& Siders W. Validation of tetrapolar bioelectrical impedance method to assess human body composition. Journal of Applied Physics $1986601327-1332$.

26 Segal KR, Gutin B, Presta E, Wang J \& van Itallie T. Estimation of human body composition by electrical impedance methods: a comparative study. Journal of Applied Physics $1985 \mathbf{5 8}$ 1565-1571.

27 Snel YEM. Growth hormone deficiency in adults. Body composition, energy metabolism and effects of growth hormone replacement therapy. Thesis University Utrecht, The Netherlands 1995. Schiedam: Steens.

28 Kotler DP, Burastero S, Wang J \& Peirson RN Jr. Prediction of body cell mass, fat-free mass, and total body water with bioelectrical impedance analysis: effects of race, sex, and disease. American Journal of Clinical Nutrition $1996 \mathbf{6 4} 489 \mathrm{~S}-497 \mathrm{~S}$.

29 Segal KR, Van Loan M, Fitzgerald PI, Hodgdon JA \& Van Itallie TB. Lean body mass estimation by bioelectrical impedance analysis: a four site cross-validation study. American Journal of Clinical Nutrition $1988 \mathbf{4 7} 7-14$.

30 Edwards RHT, Young A, Hosking GP \& Jones DA. Human skeletal muscle function: description of tests and normal values. Clinical Science \& Molecular Medicine 197752 283-290.

31 Höök O \& Tornvall G. Apparatus and method for determination of isometric muscle strength. Scandinavian Journal of Rehabilitation 19691 139-142.

32 Bassey EJ \& Short AH. A new method for measuring power output in a single leg extension: feasibility, reliability and validity. European Journal of Applied Physiology 199060 385-390.

33 Anderson WF \& Cowan NR. Handgrip pressure in older people. British Journal of Preventive and Social Medicine 196620 141-147.

34 Lindsay R, Cosman F, Herrington BS \& Himmelstein S. Bone mass and body composition in normal women. Journal of Bone and Mineral Research 19927 55-63.

35 Bergstrom A, Pisani P, Tenet V, Wolk A \& Adami HO. Overweight as an avoidable cause of cancer in Europe. International Journal of Cancer $200191421-430$.

36 Morley JE, Baumgartner RN, Roubenoff R, Mayer J \& Nair KS. Sarcopenia. Journal of Laboratory and Clinical Medicine 2001137 231-293.

37 Francucci CM, Daniele P, Iori N, Camiletti A, Massi F \& Boscaro M. Effects of raloxifene on body fat distribution and lipid profile in healthy post-menopausal women. Journal of Endocrinological Investigation $2005 \mathbf{2 8}$ 623-631.

38 Ribom EL, Piehl-Aulin K, Ljunghall S, Ljunggren Ö \& Naessén T. Six months of hormone replacement therapy does not influence muscle strength in postmenopausal women. Science Direct 2002 42 225-237.

39 Armstrong AL, Oborne J, Coupland CAC, Macpherson MB, Bassey EJ \& Wallace WA. Effects of hormone replacement therapy on muscle performance and balance in post-menopausal women. Clinical Science 199691 685-690.

40 Nijland EA, Weijmar Schultz WCM \& Davis SR. Effects of tibolone and raloxifene on health-related quality of life and sexual function. Maturitas $2007 \mathbf{5 8} 164-173$.

Received 26 October 2009

Accepted 30 October 2009 